\title{
Effect of Short Term Naturopathy Interventions on Anemia: A Single Case Report
}

\begin{abstract}
Authors
Pradeep MK Nair ${ }^{1 \Omega}$, Shahana $\mathrm{S}^{2}$, Salwa $\mathrm{H}^{3}$

${ }^{1}$ BNYS*, MSc Clin ${ }^{\alpha}$ Res, Physician, National Institute of Naturopathy, Ministry of AYUSH, Government of India, Office of Research and Development, India

${ }^{2}$ Shahana Saludeen, BNYS*, Physician, Sivaraj Naturopathy and Yoga Medical College, Salem

${ }^{3}$ Hyndavi Salwa, BNYS,MPH , Physician, National Institute of Naturopathy, Ministry of AYUSH,

Government of India, Office of Research and Development, India

*BNYS- Bachelor of Naturopathy \& Yogic Sciences, ${ }^{\alpha}$ Msc Clin Res- Master of science Clinical research,

\#MPH- Master of Public Health

${ }^{\Omega}$ Corresponding Author

Dr Pradeep MK Nair

National Institute of Naturopathy, Ministry of AYUSH

Government of India, Office of Research and Development

Tadiwala Road, Pune, Maharashtra-411001 India

Email: drpradeep18bnys@ gmail.com, Phone +919823262179, Fax: 020-26059131

Abstract

A 33 year old female diagnosed with iron deficiency Anemia in November 2014 visited National Institute of Naturopathy, OPD with complaints of lethargy, weakness, dry itchy skin and myalgia of shoulder and neck. She also expressed weakness post minor household works. Patient was not under any medications. A modified protocol of naturopathy treatments enduring for 6 days, with each session lasting for 90 minutes was devised which included hydrotherapy, mud therapy, massage and electrotherapy. Assessments were based on the changes in hemoglobin $(\mathrm{Hb})$ level from the blood sample collected on first day and sixth day of the one week session. Our patient showed an escalation in the $\mathrm{Hb}$ level from $7 \mathrm{~g} / \mathrm{dl}$ to $8.2 \mathrm{~g} / \mathrm{dl}$ at the end of six days, suggesting a positive effect of naturopathy treatments in anemia. Literature also suggests that naturopathy modalities like hydrotherapy; mud therapy etc may play a role in improving the hematological status of the body. Naturopathy, a drugless system of medicine can bring clinically significant changes in Hb levels and should be considered as a potential tool for treating anemia. However large scale randomized studies has to be conducted in this area for warranting better results.

Keywords: Anemia, Naturopathy, Hemoglobin.
\end{abstract}

\section{INTRODUCTION}

Anemia has major consequences on human health as well as social and economic development and is the second leading causes of disability in the world. ${ }^{1}$ There are many conventional therapies available for treating anemia. But reports on naturopathic treatments for anemia are scarce. Here we report the changes in hemoglobin $(\mathrm{Hb})$ level post naturopathic intervention of a patient diagnosed with iron deficiency anemia. 


\section{CASE DESCRIPTION}

Our patient is 33 year old unmarried women diagnosed with iron deficiency anemia in November 2014. Her symptoms started with tiredness and fatigue even after minor household works. She also presented with myalgia of shoulder and upper back along with dry itchy skin. She visited our outpatient department (OPD) of National Institute of Naturopathy (NIN) in $14^{\text {th }}$ November, 2014 with an $\mathrm{Hb}$ level of $7 \mathrm{gm} / \mathrm{dL}$. Though advised for the intake of iron and folic acid supplements by the conventional physician the patient was disinterested to take the supplements.

At NIN's OPD she was advised for one week naturopathy treatments devised by one of the investigator SS who is an institutionally qualified naturopath having 12 months experience. Written consent was obtained from the patient prior to the start of the therapies. The patient presented with circulatory ring $^{2}$ and a lesion in right iris 8-7 O' clock region, which is a typical diagnosis feature for anemia as per iridiagnosis ${ }^{2}$, a method used in naturopathy to diagnose disease. She also had a feeble pulse and dark circle around the eyes. On counseling the patient revealed about her improper food habits and sedentary lifestyle as the contributing factor for her troubles. Hence the naturopathic interventions were primarily aimed to correct the lifestyle and secondarily to offer physiological improvement. She underwent hydrotherapy, mud therapy, massage and electrotherapy at NIN OPD. These treatments were given in line with the basic principle of naturopathy which considers body as a whole rather than a single unit. ${ }^{3}$ The daily treatments are shown in Table 1.

Our patient was advised to come to the clinic for 6 days for six sessions, each sessions lasting for 90 minutes. Naturopathy treatments were intended for producing circulatory effects while the electrotherapy treatments such as Interferential therapy, low intensity ultrasound, infra red rays were given mainly to provide symptomatic relief from pain.
Vibro (Powder) massage, is done by applying talcum powder as a medium and the movements are performed with a vibrator machine for 15 minutes. It is indicated in improving circulatory and nervous system functions. ${ }^{4}$ Immunocorrective effects of mud therapy have been demonstrated in a clinical-immunological study. ${ }^{5}$ Mud pack was prepared with the clay which was grinded, sieved, mixed with cold water, and it was made with consistency like soft dough. This mud was spread on a strip of cloth with the dimensions $20 \mathrm{~cm} \times 10 \mathrm{~cm} \times 2.5 \mathrm{~cm}$. The pack was applied on the lower abdomen (from the navel to the pubis) and above the eyes. ${ }^{4}$ The duration of the treatment is 20 minutes.

The sitz bath/Hip bath (partial immersion bath of the pelvic region) is given in a specially constructed tub. The tub or basin was filled with enough water to cover the buttocks and hips so that the water reaches the level of the navel. ${ }^{6}$ Patient is asked to sit in the tub for 20 minutes. Enema is injection of water in to the rectum, normally given in a lithotomy position. Usually $500 \mathrm{ml}$ to 1 liter of water is administered; it is helpful in relieving inflammatory conditions of colon, ulcerative colitis, improving the digestive conditions etc. ${ }^{4}$ Swedish massage is given to the local parts for 10 minutes and full body massage for 45 minutes duration, during the six days. Massage as demonstrated in studies meliorates the circulation, in addition to the elevation in body temperature which in turn provides the escalation in pulmonary ventilation, saturation of venous blood vessels and oxygen, thereby increasing the alkanity of blood. ${ }^{7}$

Spinal spray, a modified version of spinal bath is given for 15 minutes in a spinal bath tub with specialized jets, which is designed in such a way that the entire length of the spine from the nape of the neck to the lowest portion of the spine gets jet shower. The applications of water to the spine can influence all the spinal ganglias' which are related to the sensory, heat, vasomotor and secretory centers $^{8}$ which may act by reflex action on the body organs to maintain the homeostasis. Immersion bath is also known as full tub bath. 
Taken for a duration of 15 minutes, patient have to be immersed till neck level in a bath tub, indicated in case of rheumatism, arthritis and all types of chronic diseases etc. ${ }^{4}$

Abdominal pack is made with two cotton clothes 2-2 $1 / 2$ meters long and $1 / 2$ meter wide should be dipped in cold water and wrapped around the abdomen after wringing out the excess water. After wrapping this, wrap a dry flannel or blanket of 1 meter long and $1 / 2$ meter wide around the cotton cloth for 45 minutes once in a day. This helps in relieving digestive troubles and improves the circulation to the abdominal organs. ${ }^{4}$ Additionally diet and lifestyle counseling was given post intervention, emphasizing more on iron rich food items, water intake and regular yoga practice.

\section{RESULTS}

A thorough case history was taken before the patient initiated treatments at our OPD. After initial counseling resting blood pressure, pulse and respiratory rate were measured. $5 \mathrm{ml}$ blood was collected and $\mathrm{Hb}$ level of the patient was measured by using fully automated haematologic analyzer. The patient was asked to maintain a hand diary at home to note her daily activities to ensure that she is strictly adhering to the diet and yoga practice. At the end of 6 days the post $\mathrm{Hb}$ level, resting blood pressure, pulse and respiratory rate were measured. No changes were observed in the vitals, but there was a clinically significant improvement in the $\mathrm{Hb}$ level. Pre treatment and post treatment measures are summarized in Table 2. The vitals remained unchanged after the one week treatment.

Table 1: Treatments given at NIN OPD

\begin{tabular}{|l|l|c|c|}
\hline Sl.No & Variables & Pre & Post \\
\hline & Haemoglobin $(\mathrm{gm} / \mathrm{dL})$ & $7 \mathrm{gm} / \mathrm{dl}$ & $8.2 \mathrm{gm} / \mathrm{dl}$ \\
\hline & RBP $^{*}(\mathrm{~mm} / \mathrm{Hg})$ & $110 / 80$ & $110 / 80$ \\
\hline & PR $^{\mathrm{T}}$ (Beats/Min) & 72 & 72 \\
\hline & RR $^{\text {Il }}$ (Breath/Min) & 16 & 16 \\
\hline
\end{tabular}

Table 2: Results

\begin{tabular}{|l|l|}
\hline Days & Interventions \\
\hline Day 1 & $\begin{array}{l}\text { Vibro massage to back (10 mins), Mud pack to eyes and abdomen(20 Mins), Neutral Hip } \\
\text { Bath(20 Mins) }\end{array}$ \\
\hline Day 2 & $\begin{array}{l}\text { Neutral enema, Partial oil Massage to back, neck and shoulder(10 mins), Infra red rays to back } \\
\text { neck and shoulder(10 mins) }\end{array}$ \\
\hline Day 3 & Interferential therapy to back(10 mins), , Ultra Sound to neck and right shoulder(10 mins), \\
\hline Day 4 & Full Body massage(45 mins), Neutral spinal spray (15 mins), \\
\hline Day 5 & $\begin{array}{l}\text { Cold abdomen pack(20 mins), Neutral Hip Bath(20 mins), Ultra Sound to neck and right } \\
\text { shoulder (10 mins) }\end{array}$ \\
\hline Day 6 & $\begin{array}{l}\text { Mud pack to eyes and abdomen(20 mins), , Neutral Immersion Bath(15 mins), Interferential } \\
\text { therapy to neck(10 mins) }\end{array}$ \\
\hline
\end{tabular}

*RBP- Resting Blood Pressure, ${ }^{\mathrm{T}} \mathrm{PR}$ - Pulse rate, ${ }^{\mathrm{g}} \mathrm{RR}$ - respiratory Rate

\section{Literature Review}

Naturopathy interventions individually have shown to have positive effects on circulatory system. Mud pack has shown improvement in the microcirculation and vasomotion score as reported by Poensin $\mathrm{D}$ et al. ${ }^{9}$ Hidetoshi $\mathrm{M}$ in his study implicated the effects of massage to increase the skin blood volume and elevation in the skin 
temperature $^{10}$ suggesting a circulatory reaction after massage. Literature also suggests that cold exposure to small surface area produces compensatory vasodilatation in deeper vascular system resulting increased blood flow to the tissues underlying the site of exposure. ${ }^{11}$ which may help to improve the tissue hypoxia as well ischaemia.

\section{DISCUSSION}

One week naturopathy and yoga intervention has shown clinically significant change in the $\mathrm{Hb}$ level as shown in our case. There is an increase in 1.2 $\mathrm{gm} / \mathrm{dl}$ in $\mathrm{Hb}$ which implicates the possibility of naturopathy intervention to be used as a potential tool for managing anemia. The patient also expressed moderate relief in lethargy and weakness. Longer duration of naturopathy treatments have to be studied for inferring further changes. No attempts were made to follow up of this case to find the sustainability of the results. However our results are based on a single case, large scale randomized studies has to be conducted in this area for warranting better results.

\section{CONCLUSION}

To our knowledge this is the first study to report the effect of naturopathy interventions on anaemia. Naturopathic Medicine is a drugless system of medicine which uses body's inherent power to treat diseases. ${ }^{3}$ Anaemia, a global threat especially affecting vulnerable groups like young adolescent girls, pregnant women and lactating mothers. Naturopathy can serve as a preventive or therapeutic modality in ameliorating anemia. However further studies have to be initiated in a larger scale to validate the results, as this is a single case report.

\section{ACKNOWLEDGEMENT}

The authors would like to thank the Ministry of Ayurveda, Yoga- Naturopathy, Unanai, Siddha, Homeopathy (AYUSH) for their support.

\section{REFERENCE}

1. Karine Tolentino, Jennifer F. Friedman. An Update on Anaemia in Less Developed Countries. Am J Trop Med Hyg. 2007;77:44-51.

2. Jenson B, Bodeen D. Visions of Health: Understanding Iridiology. $1^{\text {st }}$ edition.USA: Penguin Putnam Inc.1992:125-29.

3. Nair PMK, Nanda A. Naturopathic medicine in India, Focus on Alternative and Complementary Therapies. 2014;17: 140-147.

4. Nature cure treatment. $2^{\text {nd }}$ ed. Bangalore, India: Institute of naturopathy and yogic sciences. 1994.

5. Musaev AV, Imamverdieva SS, Kerimbei li US. Pelotherapy of patients with diabetic poloyneuropathy: a clinical-immunological study. Zh Nevrol Psikhiatr Im S S Korsakova. 2008;108:17-23.

6. Mamidi P ,Gupta K. Efficacy of certain yogic and naturopathic procedures in premature ejaculation: A pilot study. Int $\mathbf{J}$ Yoga. 2013;6:118-22.

7. Pemberton R. The physiologic effect of massage. JAMA. 1924;83:1761-1763.

8. Kellog JH. Rational Hydrotherapy. $3^{\text {rd }}$ Edition. Pune, India: National Institute of Naturopathy. 2005:72.

9. Poensin D et al. effects of mud pack treatment on skin microcirculation. Joint None Spine. 2003;70:367-70

10. Hidetoshi M. Effects of massage on blood volume and muscle fatigue following isometric lumbar exercise. Med Sci Monit. 2004;10:173-8.

11. Weston M, Taber C, Casagranda L, et al. Changes in local blood volume during cold gel pack application to traumatized ankles. J Orthop Sports Phys Ther. 1994; 19:197-9 